\title{
Cómo y por qué me encontré escribiendo relatos para niños
}

\section{Eduardo Chirinos}

Resumen

El poeta Eduardo Chirinos presenta en este ensayo su experiencia como lector, su experiencia como escritor de literatura infantil y el proceso de creación del libro El koala Guilherme.

Palabras clave: Eduardo Chirinos, literatura infantil, creación literaria

Abstract

Poet Eduardo Chirinos presents here his experience as a lector, as a writer, and the creative process of El koala Guilherme.

Key words: Eduardo Chirinos, children's literature, creative writting

A la memoria de mi tía Rosa, quien me regaló mis primeros cuentos para niños.

$\mathrm{D}$ ebido tal vez a mis incapacidades auditivas (a las que debo más hallazgos que a la miopía y al astigmatismo) de niño me gustaba leer. Como en mi casa no había una biblioteca formal ni heredada, es difícil recordar el momento en que caí rendido por primera vez ante un libro. Pero debió haber ocurrido muy pronto, pues a los siete años contaba con un estante y un pequeño escritorio que mi papá le había encargado a un carpintero. Allí atesoraba —además de los cuentos que me leía mi abuela antes de dormir - los que mi tía Rosa me prestaba cada sábado con religiosa 
puntualidad. Eran libros infantiles que se leían en los años cuarenta y que ella conservaba amorosamente a juzgar por el cuidado de los forros y la esmerada letra Palmer con la que dibujaba su nombre. Los recuerdo perfectamente: La hormiguita viajera y El Mono relojero, de Constancio C. Vigil (de quien se cuenta que poseía una de las colecciones de literatura pornográfica más grande de Hispanoamérica); un Pinocho ilustrado por Carlo Chiostri, que en nada se parecía al que vi años después en el cine; una versión de $E l$ Mago de $O z$, cuyos dibujos a tinta perturbaron para siempre mis noches. No se trataba de ningún traspaso simbólico. Como la mayoría de niños normales, mis primos también detestaban los libros, así que me convertí en el único depositario de esa colección, ganándole ese derecho a la humedad y a las polillas.

De acuerdo a un juicio que combinaba bastante bien sus expectativas con mi curiosidad, mi tía Rosa calibraba el peso de los libros que me iba prestando sin esperar a que se los devolviera. Así pasé de esos cuentos infantiles a las disparatadas aventuras de Guillermo Brown de Richmal Crompton (la hija solterona de un pastor anglicano a quien le debo tardes enteras de diversión) y a los relatos de Rutley C. Bernard donde los animales salvajes eran nobilísimos héroes con nombre propio: Loki el lobo, Thunda el búfalo y Timur el tigre. De más está decir que todos esos animales se deshojaron por la incuria del tiempo o se perdieron en los numerosos viajes y mudanzas de mi familia. Años después descubrí, con envidia y nostalgia, que mi amigo Fernando Iwasaki tenía la colección completa en su casa de Sevilla.

\section{Robert Creeley cuenta con} admiración que su amigo Basil Bunting tuvo el reconocimiento de que iba a ser poeta a los cuatro años, sentado junto a una chimenea, mientras sus padres discutían sobre la guerra ruso-japonesa. A mí me gustaría tener el recuerdo de ese momento tan decisivo, pero las equivalencias ni siquiera funcionan: las casas de Lima no tienen chimenea, mis padres nunca discutieron sobre la guerra de Vietnam, y a los cuatro años no tenía el menor interés en leer y escribir. En mi caso todo eso apareció tardíamente y al lado de lecturas populares que supieron dejar huella en mi memoria afectiva. Como lo sabe cualquiera que haya sido niño en los años sesenta, la lectura de los libros «serios» tenía su competencia más fuerte en las historietas de la editorial Novaro que inundaban los kioscos de Lima. Por suerte mis padres nunca me las prohibieron: toneladas de historietas de Batman, Superman, Popeye, La pequeña Lulú y Daniel el travieso fueron devoradas con la misma pasión y la misma seriedad que los libros de mi tía Rosa. 
A finales de 1968 sorprendí a mis padres cuando me preguntaron qué quería como regalo de navidad. Con la seguridad y el aplomo de mis ocho ańos les contesté «Una enciclopedia de seis tomos». No sé si mis padres se aguantaron la risa (conociéndolos diría que sí), pero lo cierto es que me la compraron, y que a partir de esa navidad esos seis tomos pasaron a ocupar un lugar preferencial en mi pequeño estante. Se trataba de un mundo que, por primera vez, advertía al alcance de la mano: historias del antiguo testamento, de la mitología griega, de personajes ilustres, además de adaptaciones de obras literarias y los siempre bienvenidos animales. A mis ocho

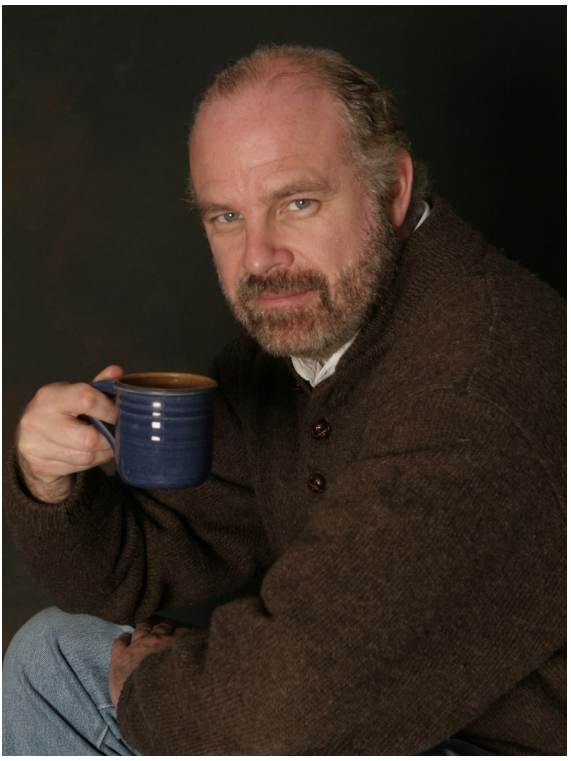
Germán - Berdiales otros poetas que ahora no puedo recordar. Lo que sí recuerdo es la indiferencia que me producían esas páginas que me saltaba sin ningún escrúpulo. Después de tantos años he comprendido que la poesía estaba en todas las secciones de esa enciclopedia excepto en la de «Poesías», donde se daba como un años ya había visto a Judith cortando la cabeza de Holofernes, a Faetón el temerario robando el carro de Apolo, a Benjamín Franklin persuadiendo rayos con una cometa, a Plancarpino y Rubroeckviajando al corazón de Asia, al elusivo okapi paseándose en las montañas húmedas del Congo. ${ }^{1} \mathrm{El}$ mundo estaba a solas conmigo, y lo mejor era que podía escucharlo sin tener que pasar por niño tonto, como probablemente me

consideraban los maestros a quienes no escuchaba porque no podía. O simplemente Pero no todo era atractivo en esa enciclopedia. Había en ella una sección de «Poesías» en la que figuraban versos invariablemente rimados de Amado Nervo, Gabriela Mistral, Juana de Ibarbourou, y 
la música puede prescindir del argumento, incluso de los significados (¿a qué otra cosa aspira la mejor poesía?), pero también es verdad que, una vez adquirido el lenguaje, el niño convierte automáticamente esos juegos rítmicos y fónicos en herramientas para retener en la memoria aquello que le cuentan. Ni más ni menos como el auditorio que escuchaba durante horas a los rapsodas y juglares. ¿Escribir para niños? No gracias. Lo consideraba un reto demasiado grande, y no me gustaba la idea de que los niños pasaran de largo ante a mis esfuerzos como yo mismo pasé de largo ante poetas que ahora admiro. Pero ese «no gracias» nunca se lo creyeron ni mi familia ni mis amigos, quienes me consideraban más capacitado para escribir las historias con las que entretenía a sus hijos que los poemas y ensayos que muchas veces no entendían. Por años preferí dejar que la espontaneidad narrativa mantuviera su carácter de performance que, estaba seguro, se arruinaría una vez que me sentara a poner las historias por escrito. ¿Cómo entonces me animé a escribir e ilustrar la primera novelita del Koala Guilherme?

La historia es larga y trataré de abreviarla. Empezaré con mi amiga, la reina Isabel de Portugal. Isabel Aguiar Barcelós es una poeta nacida en las islas Madeira, frente a la costa Atlántica de Marruecos. La conocí a finales del siglo XX, cuando la comunicación por internet todavía no se había generalizado y la gente se enviaba cartas en sobres llenos de misterio y estampillas. Isabel fue mi última amiga epistolar. Durante dos años recibí cartas suyas en las que me contaba, en correctísimo castellano, acerca de los avances de su antología sobre el mar en la poesía hispanoamericana, de los poemas que estaba escribiendo, de los pintores que más le interesaban (por ella descubrí a Lucian Freud y a Egon Schiele) y de su proyecto de libros para niños en colaboración con la artista Isabel Rodrigues Konrad. Incluso llegó a enviarme los borradores de algunos de esos libros: El perro Farruco, El burro Anastasio, El gato pompón, El koala Guilherme. Ninguna de estas cándidas historias (que nada tenían que ver con las de Rutley C. Bernard) sobrepasaba las diez páginas, y todas fueron publicadas al año siguiente. Todas... excepto la que más había despertado mi curiosidad: la del koala que llevaba el mismo nombre de mi héroe Guillermo Brown. La ocasión de preguntárselo ocurrió una tarde de febrero del año 2000, cuando me telefoneó desde Lisboa «para ver si mi voz se parecía a mi letra». Como imagino que es su costumbre, Isabel me contestó con otra pregunta: «iA Jannine y a ti les importaría quedarse un tiempo con Guilherme?». Me dijo que tenía planeado viajar a Milán con su esposo y sus dos hijos para adoptar otro koala que le hiciera compañía al pobre Guilherme, y 
no tenían con quien dejarlo. No supe qué decirle. Luego de algunos segundos (un poco más largos que los recomendables) le expliqué amablemente que era imposible, que Jannine y yo teníamos mucho trabajo en la universidad, que estamos muy ocupados con nuestras cosas y no teníamos la menor idea de qué hacer con un koala. Además, ¿cómo lo iba a enviar a Missoula desde Lisboa? «Muy fácil», me dijo como si tuviera la respuesta preparada, «esta misma noche a las 8:00 te lo envío por internet. Eso sí, te pido que me escribas diariamente contándome cómo se porta, pues lo voy a extrañar mucho». Y colgó.

Para entonces, las cartas manuscritas habían pasado a la historia, y tanto Isabel como yo habíamos adoptado el internet para comunicarnos. Lo que jamás se me había ocurrido era que alguien adoptara el internet para enviarme un koala desde el otro lado del mundo. Así que a las 7:55 de esa misma noche Jannine y yo estábamos sentados frente a la pantalla del ordenador, esperando a nuestro joven e inusual huésped. Y así comenzó todo. Sin que nos lo propusiéramos formalmente empezó a construirse una historia en la que Guilherme adquirió vida propia al margen de la voluntad de Isabel y, por supuesto, de la mía. De más está decir que Jannine y yo nos encarińamos con el koala - y él con nosotros- y que Isabel estaba tan feliz que hasta permitió que nos quedáramos con él más tiempo de lo pactado. Incluso llegó al punto de confesarme que esperaba con ansiedad los mensajes donde le contaba las travesuras de Guilherme, y yo al punto de sorprenderme con sus ocurrencias y dibujándolo para darle el cuerpo y la expresión que imaginaba.

El verano del 2003 lo pasamos en España gracias a una beca que Jannine obtuvo para investigar en el Archivo de Indias, y decidimos viajar a Lisboa. Luego de casi cuatro años de intercambios epistolares, correos electrónicos y llamadas por teléfono, queríamos conocer en persona a la reina Isabel. Como para entonces tenía acumulados muchísimos correos en tres lenguas (Isabel escribía en portugués, yo en español y Guilherme en koalés) reuní todas nuestras cartas, les añadí algunos dibujos, las encuaderné y se las llevé como un regalo personal. Como era de esperar, Isabel se puso contentísima y me hizo notar que esos correos contenían una historia para niños, pero claro, había que editarla, traducirla a una sola lengua y, si era necesario, reescribirla. Luego me alentó a que incluyera más dibujos y que buscara algún editor en el Perú o en Espańa. Y bueno, eso fue lo que hice: después de traducirlo al español (dejando las palabras más bonitas en portugués original), seleccioné algunos dibujos, hice otros, reescribí partes de la historia, y le llevé 
la versión final a quien considero el mejor narrador para niños que hay en el Perú, mi amigo Jorge Eslava. Cuando le mostré la novelita con las ilustraciones me dijo silabeando cada palabra para que pudiera escucharlo: "Querido Edu, desde que te conozco he estado esperando que escribieras y dibujaras tu propia historia para niños».
Yo también lo esperaba. Desde la mañana del 25 de diciembre de 1967 , mientras acomodaba los seis tomos de la enciclopedia en el pequeño estante que me regaló mi papá. 